This PDF is a selection from a published volume from the National Bureau of Economic Research

Volume Title: A New Architecture for the U.S. National Accounts

Volume Author/Editor: Dale W. Jorgenson, J. Steven Landefeld, and William D. Nordhaus, editors

Volume Publisher: University of Chicago Press

Volume ISBN: 0-226-41084-6

Volume URL: http://www.nber.org/books/jorg06-1

Conference Date: April 16-17, 2004

Publication Date: May 2006

Title: Principles of National Accounting For Nonmarket Accounts

Author: William D. Nordhaus,

URL: http://www.nber.org/chapters/c0135 


\title{
Principles of National Accounting For Nonmarket Accounts
}

\author{
William D. Nordhaus
}

\subsection{Background and Purpose}

The purpose of this essay is to sketch the major principles that might be used in the design and implementation of a set of augmented national accounts. By augmented accounts I mean an integrated set of accounts for both market and nonmarket economic activity. Since the major missing components of a set of augmented accounts are nonmarket in nature, I focus primarily on those activities. This note builds on the principles developed for environmental accounts in Nature's Numbers (Nordhaus and Kokkelenberg 2000) and fills in some of the gaps for other sectors.

Augmented accounts should be designed to follow two general principles: First, they should address the major conceptual issues by measuring income and output in ways that best correspond to net economic welfare. Second, they should include both market and nonmarket activities.

Augmented accounts are designed to illuminate that part of human economic activity that takes place outside the market place and/or outside the core national economic accounts. Some of the important areas include natural resources, unpaid work, investment in education and health, and the environment.

William D. Nordhaus is Sterling Professor of Economics at Yale University and a research associate of the National Bureau of Economic Research.

The author is grateful for comments by Katharine Abraham, Chris Mackie, and Robert Mendelsohn. This paper is an expanded version of one prepared for the National Research Council (NRC) panel "Designing Nonmarket Accounts for the United States," drawing on the lessons learned from the NRC study Nature's Numbers: Expanding the National Economic Accounts to Include the Environment (Nordhaus and Kokkelenberg 2000). The report of the NRC panel is contained in Abraham and Mackie (2005), but the analysis of that report is not reflected in the current analysis. 
Before getting down to details, I must emphasize that, while nonmarket and environmental accounts can form an important addition to our understanding of economic activity, they are not ready for center stage. It would not be advisable to incorporate further major nonmarket activities into the core National Income and Product Accounts at this time. Nor can we sensibly recommend that the state of nonmarket accounts is more than experimental in the United States at this time. However, it would be sensible to set as a goal of the U.S. statistical system to develop satellite nonmarket accounts in different areas in the years ahead.

\subsection{Fundamental Accounting Framework}

The first question raised in the practical construction of any accounting system concerns the accounting framework. The natural starting point for augmented accounts, and the one that in my view will best withstand careful scrutiny, is to use the economic principles underlying the national economic accounts (called here "NEA design"). These accounts include a full set of current and capital accounts along with the accounts linking the current and capital accounts where that is possible.

The rationale for using NEA design as the jumping-off point for nonmarket accounts is based on two fundamental advantages. First, NEA design has been the subject of extensive research and practical experience for many decades. The principles of the NEA have been carefully thought out; practice has shown that they can be implemented; and they have a rough correspondence with economic welfare. Second, many questions of augmented accounts have counterparts and therefore answers in the NEA design, so they can serve as a point of departure for augmented accounts design.

Although the general principles of NEA accounting are straightforward, in fact, there are several different models, and actual practice differs among different systems.

1. One set of accounts is the national income and product accounts (NIPAs) and satellite environmental accounts of the United States. This is probably the best-known set of accounts and could usefully serve as a model. They are, however, at this time incomplete in certain respects, and nonmarket accounts should incorporate current principles.

2. There are two versions of the internationally developed System of National Accounts (SNA), the latest being 1993. ${ }^{1}$ The major feature of the SNA is that it contains multiple sets of accounts linking production, income, consumption, accumulation, and wealth. The integrated feature of

1. The System of National Accounts, or SNA, developed under the aegis of the United Nations and other international agencies, is a set of concepts, definitions, classifications, and accounting rules. The latest SNA is from 1993 and can be found at http://esa.un.org/unsd/ sna1993/introduction.asp. The United States has adopted most of the principles in the SNA. 
the SNA is a goal of the U.S. accounts, is a desirable feature, and should be a key element in the development of a set of nonmarket accounts.

3 . The Jorgensonian set of accounts is closely related to the SNA in developing an integrated set of accounts. The Jorgensonian accounts include nonmarket elements and an extensive set of imputations; they do not yet include a set of environmental or externality accounts. ${ }^{2}$

4. There are additionally several partial accounts that have been developed in different sectors. The accounts developed for natural resources and the environment have been surveyed in the Academy report Nature's Numbers (Nordhaus and Kokkelenberg 2000).

In considering augmented accounts design, the major issues concern the following: (a) adjustments to the NEA design that would be desirable to make augmented accounts conform more closely to a measure of economic welfare, (b) adjustments, additions, and subtractions that would be necessary to include nonmarket activities, and (c) the boundary of nonmarket accounts.

\subsubsection{Adjustments Necessary to Conform to \\ Measure of Economic Welfare}

"Output" and "income" in economic accounts should, in general, be designed to measure concepts that are consistent with economic welfare. There are many areas where current NEA design does not adequately or properly reflect economic welfare. One obvious example is the focus on gross domestic product, gross domestic income, and other measures of gross output rather than net output and income. Adjusting income and output measures to a net basis is today relatively straightforward, although there are necessarily ambiguities at the margin.

Many other examples of adjustments necessary to conform to economic welfare involve the division of gross output between intermediate products and final products. For example, the U.S. NIPAs today include military expenditures in final output, while the first national accounts included only civilian output. Similar questions arise for expenditures on police, security, and pollution control, which might be classified as "defensive" rather than final expenditures.

In part, the need for rethinking the definition of output arises because nonmarket accounts might choose to tailor their design to economic welfare rather than, as in the NEA, primarily as a measure of current production and income. More important in this context is that we include

2. The Jorgenson set of accounts is described in Barbara Fraumeni's "The Jorgenson System of National Accounting" (1999). This overview provides a good description of the underlying philosophy. Note that the major difference between these accounts and the SNA is the extensive use of imputations of income and output from capital stocks as well as the development of extensive nonmarket accounts. 
instrumental expenditures because the goods or services to which they are devoted are either nonmarket activities or imperfectly measured and are excluded from the core accounts. For example, if losses from burglary were part of the nonmarket accounts, then both those losses and home-security expenditures could be excluded from final product; then an expenditure on home security that reduced burglary losses by the same amount would be correctly treated as a zero change in net welfare. Similar issues arise with respect to pollution-control expenditures and the nonmarket impacts of pollution.

\subsubsection{Adjustments, Additions, and Subtractions That Would Be Necessary to Include Nonmarket Activities}

The next issue concerns the appropriate treatment of nonmarket activities. It should be noted that the accounts already include a substantial value of such activities, including owner-occupied housing and food consumed on farms. A natural principle for treating nonmarket activity is the following:

Basic principle for measuring nonmarket activity. Nonmarket goods and services should be treated as if they were produced and consumed as market activities. Under this convention, the prices of nonmarket goods and services should be imputed on the basis of the comparable market goods and services.

For example, if households gather ten pints of berries in the national forests, then the price attributed to that activity should be the price of berries of equivalent quality in that location. There may be formidable practical issues in implementing this fundamental principle, but the underlying logic is clear.

\section{Near-Market Goods and Services}

One important distinction in this regard is whether or not goods and services are "near-market." A near-market good or service is one that has a direct counterpart in the market (firewood, berries, owner-occupied housing, and homegrown tomatoes). Near-market goods and services obey the "third-party rule," which states that a third party could produce the good or service just as well as the party that produces the item.

\section{Personal Goods and Services}

The complementary case has no name but might be called personal goods and services, indicating that these items can only be produced by the consumer. Personal goods and services do not obey the third-party rule. Their prices cannot be observed because no transactions occur in markets, although behavioral traces of the valuation of personal goods can be found 
in household decisions. The clearest example of a personal commodity is leisure time; no one can produce leisure for me. There are no market transactions for personal goods and services, and we must rely upon imputed or implicit prices. For the case of leisure, we normally impute its value by assuming that individuals optimize their time use, which ordinarily implies that the value of leisure is the individual's after-tax marginal wage rate. (I return to this issue below.)

There are no major conceptual differences between near-market and personal goods. Rather, the implication of this distinction is the practical one that estimation of the value of personal nonmarket goods may be extremely difficult because there are no transactions and no market standards.

\section{Public versus Private Goods}

The other important distinction that will require analysis in an accounting context is between private and public goods and services (in the Samuelsonian sense). Private goods and services are ones that can be divided up and provided separately to different individuals, with no external benefits or costs to others. An example is bread. Ten loaves of bread can be divided up in many ways among individuals, and what one person eats cannot be eaten by others. Private goods are straightforward for economic accounting and are central to the theory behind the NEA. There are no conceptual changes that are necessary to include nonmarket private goods (either near-market or personal).

Public goods and services, by contrast, are ones whose benefits are indivisibly spread among the entire community, whether or not individuals desire to purchase them. An example is smallpox eradication. It matters not at all whether one is old or young, rich or poor, American scientist or African farmer-one will benefit from the eradication whether one wants to or not.

A major issue for nonmarket accounts, particularly environmental accounts, is the treatment of public goods (or goods with externalities). This is one area where I would suggest a revision in the treatment as compared to standard national accounting. It should be noted that public goods are already in the accounts, but there are conceptual difficulties that arise in their treatment in a complete set of accounts. There are two interesting cases: case 1, public goods where the flows are completely in the market accounts; and case 2, public goods where some of the flows are in the nonmarket sectors.

Case 1 (flows in the market sector). There are already many cases of externalities wholly in the accounts. One example is air pollution and agriculture. Suppose pollution by chemical firm A has the sole effect of reducing the production of corn of farm firm B by $\$ 100$. The entire impact of the 
activity is in the market accounts, even though there are no market transactions between the two firms.

The major issue here is whether we would want to reallocate or unpack the transactions into two offsetting transactions in a process I call externality disaggregation. In this case, firm A provides an input into firm B with a value of minus $\$ 100$, and firm $B$ provides an implicit transfer or subsidy to firm A of $\$ 100$. There would be no effect of this disaggregation on net output of the market sector, although the value added of the chemical and farming sector would change. These transactions might be illuminating in providing estimates of the size of the implicit subsidies or if the total value added of particular industries were significantly changed. It would be interesting to know, for example, the size and sign of the net output of the coal and tobacco industries if externality disaggregation were to take place.

Case 2 (flows cross the market boundary). The second case is more significant for overall flows and for the measurement of market output and income. This occurs when only part of the transactions takes place inside the market place. An example is industrial air pollution. Here, externality disaggregation might find that air pollution in the United States represented a minus $\$ 100$ billion per year negative input from the industrial sector (power plants, etc.) into the nonmarket accounts of the household sector in damages to nonmarket activity or reduction in nonmarket output. The counterpart transaction would be a $\$ 100$ billion per year implicit transfer or subsidy from the nonmarket accounts of the household sector to the industrial sector.

It should be noted that an accounting analog to externality disaggregation already exists in the accounts for some taxes. In these cases, the producer prices differ from the consumer prices, with the difference explicitly recognized on the income side as "taxes on production and imports less subsidies" (formerly, indirect business taxes). With externality disaggregation, the balancing item would be implicit subsidies. There is also a question as to whether net output would be calculated with or without the implicit subsidy; this also has a parallel in the accounts in the question of whether to measure national income at market prices or factor costs.

Note that externality disaggregation in case 2 changes the value added of both the market accounts and the nonmarket accounts, while leaving unchanged the output and income of the aggregated market and nonmarket accounts. By contrast, proper accounting in case 1 does not change the values in any of these three major aggregates. While it is illuminating but not necessary to undertake externality disaggregation for case 1 (when the externality is confined to a particular component of the total accounts), it is definitely necessary for accurate accounting to undertake externality disaggregation for case 2, where the externality crosses the border between market and nonmarket sectors. 


\subsubsection{Border Disputes}

The boundary of the market accounts is in principle clear: it involves goods and services that are transacted in markets. Probably the most difficult issue in design of augmented accounts is where to draw the border. Should they include only near-market goods? All nonmarket goods? Public goods? Global public goods? Intangible assets as well as tangible assets? The costs of crime and AIDS? The value of life, liberty, and the Constitution?

There are no clear-cut answers to these questions, but the following principles may help sort of the priorities. First, it should be emphasized that the purpose of nonmarket accounts is not to develop "accounts of everything." Rather, the purpose is to include activities that are economic in nature and those that substitute for market activities. This would suggest that unpaid work and nonmarket time devoted to research, education, and training are important targets for nonmarket accounts. Similarly, the value of "social capital" in club membership or bowling leagues would seem extremely difficult to define and measure. Second, nonmarket accounts are designed to ensure that our economic accounts are not distorted because the lines between market and nonmarket change over time. If female labor-force participation rises and moves much of female work from unpaid home production to the market, then time use is surely a candidate for inclusion to ensure that we have not overestimated per capita growth rates. Finally, some aspects of nonmarket accounts are of great relevance for policy or understanding social systems.

A closely related question involves where to begin developing nonmarket accounts. First steps will be matters of taste and interest as well as pure economic calculus. In my view, important sectors to begin are in household production, near-market sectors like forests and water, human capital, health, and pollution. These would be high on the list because they score high on the general principles listed above and because many scholars and policymakers are interested in their contribution to total economic welfare.

\subsubsection{Some Thorny Issues in Nonmarket Accounts}

There are a few additional issues relating to nonmarket accounts that are worth addressing.

\section{The Pervasive Lack of Data}

Perhaps the most important single issue is the absence of any data on quantity, price, or total value for virtually all sectors of nonmarket activity. Market accounts, by contrast, have rich data on three aspects of total values: expenditures, incomes, and production.

The following paragraph from Nature's Numbers (Nordhaus and Kokkelenberg 2000) describes the difficulties of developing accounts based on physical data for a loaf of bread: 
This section has emphasized the complexity involved in constructing environmental accounts in the absence of data on market data. Consider the problems involved in constructing accounts for a simple loaf of bread in the absence of market transactions. Doing so would require measuring and valuing a wide variety of flows of water, fertilizer, pesticides, labor, climate, and capital inputs that go into producing the wheat; the fuels, transport vehicles, emissions, weather-related delays, induced congestion, or floods involved in transportation; the molds, spores, and miscellaneous rodents and their droppings that invade the storage silos; the complex combination of human skills, equipment, and structures that go into milling the wheat; the entrepreneurship of the baker and the software in the computer-operated baking and slicing machinery; the complex chemistry and regulatory environment involved in the wrapping materials; and the evolving ecology of the distribution network.

It appears unlikely that anyone would try, and safe to conclude that no one could succeed in, describing the physical flows involved in this little loaf of bread. Fortunately, however, economic accounting does not attempt such a Herculean task. Rather, the national accounts measure all these activities by the common measuring rod of dollars. Although the dollar flows are routinely broken down into different stages - wheat, transportation, milling, baking, and distribution-one could never hope to describe the flows physically and then attach dollar values to each physical stage. Yet this is just what would be required for a full and detailed set of environmental accounts. The above comparison may give some sense of why accounting for environmental flows outside the marketplace is such a daunting task. $(120-21)^{3}$

This example suggests that a set of nonmarket accounts will inevitably be much less detailed than the current set of market accounts and that we must be relatively modest in our aspirations in this area.

\section{The Difficulties of Imputing Prices}

The deepest practical difficulty that arises in constructing nonmarket accounts involves developing valuation for nonmarket goods, services, and assets. The problem in a nutshell is that there are no observable values or prices that are the analogs to prices the Bureau of Labor Statistics finds to write down and tabulate. The issues are least severe in valuing near-market goods, moderately severe for private but "personal" goods, and extremely severe for public goods.

In practice, values are often imputed (a) by looking at behavior that reveals consumer valuation of the commodities, (b) by unbundling the commodities and valuing component parts, or (c) by using surveys. These three techniques are exemplified by the travel-cost method, hedonic regressions or analysis, and contingent-valuation surveys, respectively. In addressing these issues, the panel in Nature's Numbers recommended as follows: 
Valuation methods [in environmental accounts] should rely on available market and behavioral data wherever and whenever possible. Although there are difficulties with nonbehavioral approaches such as contingent valuation, work on the development of such novel valuation techniques will be important for developing a comprehensive set of production and asset accounts. (Nordhaus and Kokkelenberg 2000, 167)

Whatever valuation technique is used, determining values for nonmarket sectors will generally be difficult and, particularly when they involve personal goods and services, may be controversial. National-income accountants generally prefer valuation techniques that have an objective behavioral component, whether in market prices or individual actions. Valuation techniques that are largely subjective and based only on survey information alone - such as contingent valuation - are difficult to validate and should be avoided where possible, but may be needed in some areas.

\section{The Question of Consumer Surplus and the "Zero Problem"}

Often, in undertaking valuations of nonmarket activities, analysts use total values rather than marginal values (prices times quantities). In other words, they sometimes include the consumer surplus along with the marginal values. ${ }^{4}$

Is inclusion of consumer surplus appropriate? There are two points here. First, to introduce consumer surplus in the augmented accounts would introduce a major inconsistency in the accounts because the standard national accounts are based on marginal values.

Second, using consumer surplus introduces a whole new set of decisions involving the "zero level" of different activities. For example, if we introduce the consumer surplus of water consumption, then we need to integrate the marginal surpluses (the difference between demand and cost curves) between some "zero" level and current output. But this raises the issue of the "zero" level. Is it literally zero water (in which case consumer surplus is essentially infinite)? Or the level in pre-industrial times? If the latter, should pre-industrial times relate to the 1700 s, when water in the United States was plentiful? Or to the time when humans first crossed the Siberian peninsula, when ice was plentiful but water was scarce? Moreover, if we pursue consumer surplus in too many areas with low "zeroes," we will undoubtedly find ourselves with multiple infinities of output and income.

Once we travel even a few thoughts down this road, we rapidly come to the conclusion that, for purposes of measuring output and income, we should retain the standard approach of using marginal valuations in all sectors. This does not completely remove the zero problem, as I will explain in the next section, but it does ensure that we have comparability across differ-

4. An important example of an analysis using total values (including consumer surplus) is one valuing ecosystems. See Costanza et al. (1997). 
ent accounting systems and will remove the problem of dealing with large numbers of infinitely valuable sectors.

\section{Measurement of Natural Assets}

For produced assets, there is a natural measuring rod in the number and value of the production of machines, houses, software packages, and so forth, and these can be aggregated to form capital stocks. The measurement of natural assets is not obvious. What is the value of the stock of firstgrowth forests, of unproved petroleum deposits, of clean air, or of breeding potential in wild fish?

One answer, but an unattractive one in this context, is the answer of the market accounts: The traditional accounts assume that the values of natural stocks are zero because their (market) production costs are zero. We clearly need to recognize that nonmarket assets have value, and that their value can be increased or decreased through human activities.

However, once we open the door to nonzero natural stock values, then the "zero problem" level arises once again. Do we measure the value of the stock relative to "zero stock" or relative to some other benchmark; and, additionally, do we value that difference using marginal or total valuations?

This question is often discussed in the context of estimates of the "value of ecosystems," which are often taken relative to their complete absence (and presumably the absence of all life). Using a total valuation system (in essence, taking the present value of consumer surpluses), ecosystems will indeed have a near-infinite value. But so would the value of human capital, technical capital, land, air, and other essential inputs, and we are back to the problem of multiple infinities of values.

To avoid the zero problem for assets, we first need to use the marginal valuation principle, whereby the value of the stock is the quantity times the marginal value. Additionally, we may want to measure the stock relative to a recent base period, the last period, or use chain indexes. These assumptions will ensure that natural and nonmarket capital are measured consistently in the income, production, and asset accounts; that they are treated consistently with market accounts; and that their size does not overwhelm the value of capital for other sectors.

One of the reasons that it is essential to prepare an integrated set of production, income, consumption, accumulation, and wealth accounts is to ensure that the definitions are consistent across the different accounts. In the integrated production and income accounts, accumulation would be the marginal valuation times the change in the stock, in which the "zero" level of the stock is clearly irrelevant.

\section{"European" versus "American" Views on Measuring Nonreproducible Assets}

Among the many thorny issues in designing augmented accounts, one interesting controversy involves the appropriate approach to measuring 
the value of nonreproducible assets like oil and gas reserves. Our NIPAs currently contain estimates of the production and flows of mineral products through the economy. However, changes in the stocks of valuable subsoil assets are currently omitted from the NIPAs. In its prototype satellite environmental accounts (the integrated economic and environmental satellite accounts, or IEESAs), the Bureau of Economic Analysis (BEA) prepared estimates that showed the impact of including "depletions" and "additions" to stocks of mineral resources. ${ }^{5}$ The procedure, which I will call the "American approach," is straightforward. The BEA defined real net investment or net additions to mineral stocks as

$$
\text { Net investment in subsoil assets } s_{t}=N_{t}=p_{t}\left(A_{t}-D_{t}\right),
$$

where $N_{t}=$ net investment in subsoil assets in prices of year $0, A_{t}=$ quantity of additions to reserves during year $t, D_{t}=$ quantity of extraction or depletions during year $t$, and $p_{t}=$ value of reserves in the ground. Current treatment of natural resources in the NIPAs omits equation (1). The main difficulty in employing the correction in equation (1) involves estimating the value of reserves in the ground, $p_{t}$.

The BEA treats mineral additions parallel with other forms of capital formation. In this respect, the U.S. accounts differ from the United Nations' System of Integrated Environmental and Economic Accounts, or SEEA, an alternative satellite accounting system proposed by the United Nations, which I will call the "European approach." In both accounting systems, depletions are treated as negative items in net investment. ${ }^{6}$ Under SEEA, however, additions are not included as a positive item and do not appear in the production accounts as capital formation. In calculating gross domestic product (GDP), the SEEA considers as capital formation only investments in "made capital" and not mineral discoveries, treating additions as an "off-book" entry. This approach has also been used by the World Bank in its calculations of true saving. ${ }^{7}$ Hence, under SEEA, net investment in non-renewable resources is calculated as

$$
\text { Net investment in subsoil assets } t=N_{t}=-p_{t} D_{t} \text {. }
$$

5. The BEA sketched a set of environmental and resource accounts (the IEESAs) in Survey of Current Business, April 1994. This research program was shut down by Congress shortly after its first publication. These accounts and the treatment above use the older convention of measuring stocks and flows as Laspeyres indexes, but there are no important differences if chain indexes are used.

6. See United Nations (1993). This study contains a description of several alternative approaches to environmental and by analog nonmarket accounting and is widely endorsed among environmentalists. It was found generally wanting by the Academy panel in Nature's Numbers because of analytical deficiencies. An update of this marked as "final draft" was circulated in 2003 .

7. See Bolt, Matete, and Clemens (2002). 
On first blush, the approach in equation (1) seems clearly appropriate because of the symmetry in treatment of additions and subtractions to the resource stock, and if required to choose between the two, equation (1) would be preferable. However, these two approaches are polar cases of a more complete theory. Both the American and the European approaches focus on a single grade of the resource, namely reserves. A more general theory would encompass at least two different grades of the resource, proved reserves $\left(R_{1}\right)$ and unproved resources $\left(R_{2}\right)$. There are two activities. The first activities are proving reserves or transforming unproved to proved reserves, which are additions $\left(A_{t}\right)$; the second activities are producing output of the mineral from proved reserves, which are depletions $\left(D_{t}\right)$. We can associate prices, $p_{t}$ and $q_{t}$, with each of these respective quantities. In this broader conception, net output in a given year is

$$
N_{t}=p_{t}\left(A_{t}-D_{t}\right)-q_{t} A_{t} .
$$

The first term in equation (3) is identical to the treatment in the American view in including the value of the change in proved reserves. There is, however, a second term, which reflects a correction for the depletion of unproved reserves involved in converting $A_{t}$ units of unproved to proved reserves. (This could be modified to include multiple grades and prices, but the essence of the analysis would not change.)

Under the American view, there is implicitly a superabundant supply of unproved resources that can be upgraded to reserves through investment on development - somewhat akin to the vast frontier available for Americans moving west in the nineteenth century. Under this approach, $q_{t}$ is zero because unproved resources are not scarce, so equation (3) becomes identical to equation (1) once the price of unproved resources is set to zero. In other words, the BEA's treatment implicitly assumes that the shadow price on unproved resources is essentially zero.

The European approach, by contrast, implicitly assumes that the stock of unproved resources is extremely limited, perhaps because virtually all the resources have been identified and proved as the frontier disappears. In this case, the shadow price on unproved resources $\left(q_{t}\right)$ might be very close to that of proved resources. In the limit, if $q_{t}=p_{t}$, then equation (3) reduces to equation (2) and the SEEA approach is the appropriate treatment.

All this leads to the question of whether the shadow price of unproved reserves is likely to be closer to zero (the American approach) or to that of proved reserves (the European approach). A recent study finds that the prices of oil reserves in the United States over the 1982-2002 period have been stable, that reserve prices have averaged around 30 percent of the field price of oil, and that the price of unproved reserves appears to be much lower than those of reserves in production (Adelman and Watkins 2003). These three results are more consistent with the American approach than 
the European approach. Nevertheless, this is an open question that of is great importance for the correct accounting for subsoil assets.

\subsection{Issues in the Use of Time-Use Data}

\subsubsection{Centrality of Time-Use Data}

I have generally ignored specific data needs for nonmarket accounts, but I will mention one crucial area. The single most important source of data for nonmarket production and income accounts is data on how the population spends its time.

The reasoning why time use is central to nonmarket accounts is the following. Nonmarket activity consists of activities like education, recreation and other uses of leisure time, babysitting, home production of laundry and similar services, and work-related activities like commuting. The inputs into these activities consist of nonmarket and market labor, capital services, and material inputs. By far the largest component of nonmarket activity is time use. More precisely, virtually the entire value added of the nonmarket sectors comes from time inputs, while most of the nontime inputs are actually purchased in the market economy.

Consider the value of home production (such as doing the laundry) or recreation (such as golfing). The total value of such activities consists of the value of purchased market inputs (soap, washing machines, golf balls, and golf clubs) plus the value of the time spent in the activities. For example, doing the family laundry might have total value of $\$ 21$, of which $\$ 20$ (1 hour $\times \$ 20$ per hour) is the value of the time, while $\$ 1$ is the cost of the soap and washing-machine services. Whatever the relative values, virtually all the nonmarket inputs are likely to be time.

The same story holds for virtually every nonmarket activity: the major nonmarket input is labor. The one important exception might be the inputs of nonmarket environmental capital (clean air, clean water, public beaches) that enter into recreation and health activities. These examples suggest that data on time use will be the most important single component of nonmarket accounts.

In this respect, it should be noted that the United States has up to now been particularly laggard with respect to generating comprehensive and periodic time use statistics. Every other major high-income country currently collects such data. Fortunately, beginning in 2003, the Bureau of Labor Statistics began the collection of a large time-use survey for the United States (the American Time Use Survey, or ATUS). ${ }^{8}$ Starting in 2004, this survey will interview 14,000 households annually from the out-rotating 
panel of the Current Population Survey. As planned, it will be the only timeuse survey in the world to be conducted on a continuous basis. The ATUS will be an important addition to the U.S. statistical system and a crucial ingredient in the future construction of augmented accounts.

\subsubsection{Problems of Pricing Time}

The problem of imputing prices for time use is usually solved by assuming that the shadow price on time is given by the price that individuals face in the labor market. Conceptually, the price is the marginal after-tax compensation, although most studies rely upon the average wage rate. Under the assumption that individuals are always able to sell hours at their aftertax wage, this puts a natural price that can be used to value leisure, nonmarket production, and other components of time use. This approach was used by Nordhaus and Tobin (1972) and is standard in most approaches to time valuation.

An alternative approach to valuation would be direct surveys of how individuals value their time. Figure 3.1 shows the results of a compilation of surveys of U.S. households as to their enjoyment of different activities. There are two striking results of this survey. The first is that there is no obvious wedge between work and nonwork that can be interpreted as a marginal wage. Indeed, working is in the middle of the pack in terms of enjoyment. Second, there is no set of activities that could be interpreted as nonwork alternatives that cluster at a preference level that can be interpreted as the nonwork alternative valued at a distinct increment above work. Rather, there seem to be a set of distinctly disliked activities - cleaning house, grocery shopping, laundry, and going to the dentist. ${ }^{9}$

How can we understand the results of figure 3.1 in the context of our microeconomic theories of the allocation of time?

- One possible interpretation is that the enjoyment reported in figure 3.1 pertains to average rather than marginal evaluations. For example, people might report that work is on average a highly pleasurable activity even though the last hour might be valued well below marginal nonwork hours. This interpretation is consistent with the results in another survey that second jobs are less enjoyable than "work." (Robinson and Godbey 1997, 340) ${ }^{10}$

- A second possible interpretation is that the underlying microeconomic theory is misspecified because most people (or most people in the survey) are unable to sell every hour on the market at the calculated post-

9. This phenomenon was noted and discussed in Juster (1985). Juster's reading of the evidence is that disequilibrium in the labor market is the most likely source of the paradox. Juster denotes the intrinsic value or enjoyment of time as "process benefits."

10. Robinson and Godbey (1997) is the most recent survey, and it ranks work between gardening and cooking or working at home. 


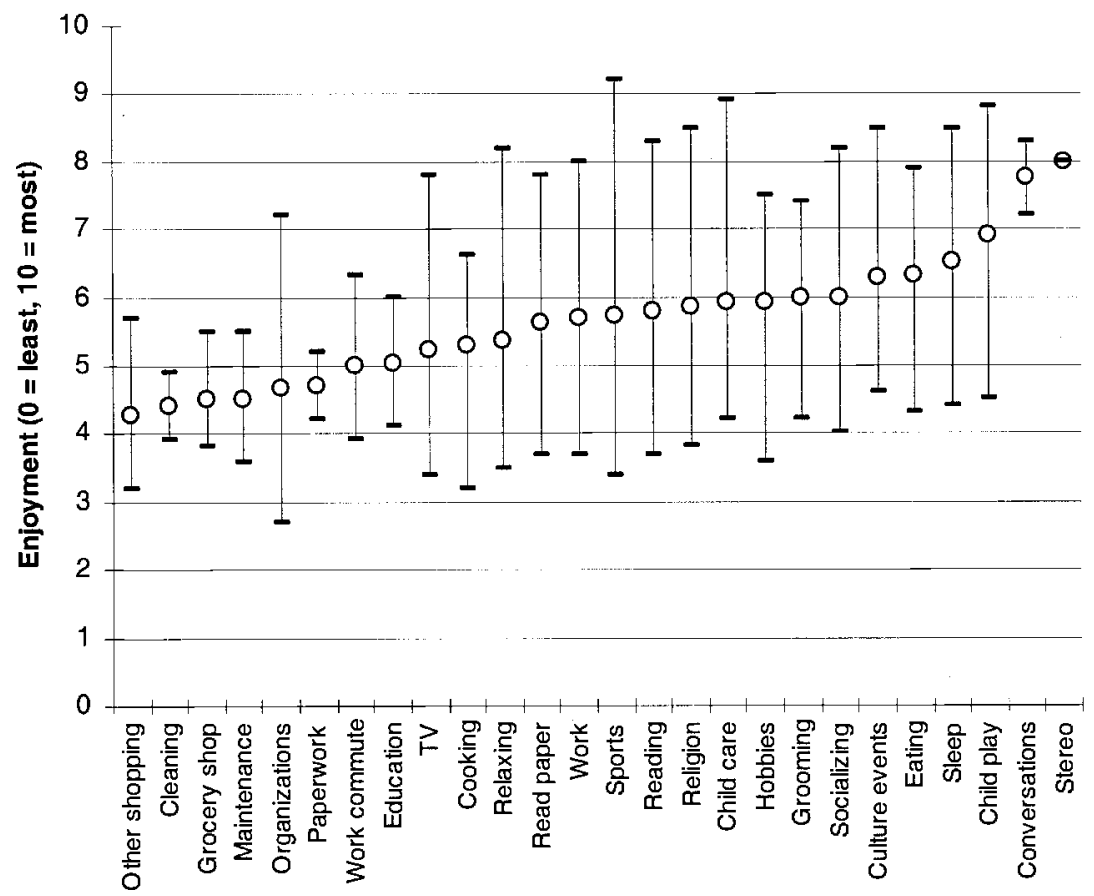

Fig. 3.1 Ranking of enjoyment of different activities

Source: Robinson and Godbey (1997, 243).

Note: The bars show the mean (as a circle) and the maxima and minima as ends of the bars for activities from five surveys over the period 1965 to 1985 with sample sizes from 133 to 2,500 .

tax wage rate. For salaried workers, the marginal wage is generally zero, while waged workers often have little control of their hours on a day-to-day basis. Self-employed workers do have control of their hours, but we do not have data on their return on marginal hours. If the marginal wage is zero for a substantial number of hours, then it would be reasonable to find that enjoyment from work would not differ markedly from enjoyment from other activities.

- A third interpretation recognizes that time is a heterogeneous commodity and that there is no reason why hours should be valued at the same rate at different times of the day and different days of the year. An analog is electricity prices, which are much like time in that neither electricity nor time can be stored. Hourly electricity prices often vary

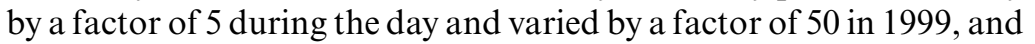
there is no reason why time prices should not vary greatly as well. For individuals facing rigid schedules (for work, school, meetings, and so 
forth), we could easily find that marginal valuations are all over the map depending on the extent of "time crunch" or "time glut."

- A fourth possibility is that the estimates are incorrect for methodological reasons and that work is in fact relatively unattractive. This interpretation is suggested by the survey of Kahneman, Krueger, Schkade, Schwarz, and Stone (2004; hereafter KKSSS). They use a method of evaluation that combines time-use diaries and day-after evaluation, whereas the studies shown in figure 3.1 use a "stylized" evaluation of the process value of activities. KKSSS find that the activities that have the lowest score of "enjoying myself" are, from the bottom, commuting, doing housework, and working. This finding matches quite neatly standard labor-market theories. However, these results are preliminary and use a highly nonrepresentative sample (women residing in two large Texas cities, with full-time employment and a high school education or better, after eliminating those who did not work the previous day). KKSSS's results suggest that the abstractions of "work" or "taking care of children" are more pleasant than the experienced reality.

In the end, we are likely to use some variant of conventional valuations of time in terms of the average after-tax wage, particularly when we cannot measure the output of the hours, but we must recognize that this convention is subject to serious reservations. This is an area ripe for serious empirical work, particularly as new time use data become available.

\subsubsection{The Problem of Simultaneous Activities}

The other major issue in applying time-use data is the treatment of simultaneous activities. How should we classify and value time use that is devoted to multiple purposes? We frequently encounter people talking on their cell phone while walking; these are clearly two distinct and inseparable activities - communicating while traveling. Another example would be activities at home. We might be dog sitting, house sitting, babysitting, listening to the radio, relaxing, visiting with family, and cooking dinner at the same time. I mentioned above the puzzle that work has such a high reported intrinsic value. Yet another possible reason is that work has positive associated activities, such as socializing. These are not isolated examples. Indeed, simultaneous time use is pervasive.

Since little time-use research to date has been economic in its orientation, little attention has been given to the problem of joint production in time use. Among the approaches used to resolve the simultaneous use question are (a) designate primary and secondary activities, (b) treat activities additively so that people might have a "thirty-six-hour day," and (c) create compound activities that treat, say, babysitting and TV watching as a different commodity. 
A new approach, which has firmer roots in economics, would be a "valuetheoretic" approach, which allocates simultaneous activities among their components on the basis of the values of the different activities. We are always doing many things. If we are doing one thing that is useful and another thing that is useless, then the value-theoretic approach would hold that our time is devoted to the useful activity. For example, suppose I am tending for my small children, which is important, while looking at internet advertisements, which has no value. Then this approach would find that the time is spent entirely in tending for children. Valuing time devoted to simultaneously cooking mutton and washing wool socks would be similar to valuing the joint products of mutton and wool from sheep.

This approach can be illustrated by examining near-market goods and services. Suppose that during an hour I produce simultaneous babysitting services and dinner. Say that the value of babysitting services is $\$ 5$ per hour and cooking services is worth $\$ 10$ per hour. Then we would say that the hour was divided into twenty minutes of babysitting and forty minutes of cooking. Again, this methodology would give the same answer as traditional approaches if the first twenty minutes were babysitting and the second forty minutes were cooking. (For nonmarket activities, we would use relative utility valuations.)

One reason why the value-theoretic approach helps in considering simultaneous activities is that traditional approaches tend to emphasize the physical and locational aspects of time use. For example, if I am eating dinner and visiting with the family, the physical activity of eating will generally be classified as the principal activity and the visiting will be either ignored or classified as the secondary activity. In fact, the visiting might be the more important, and would be classified as such in the value-theoretic approach.

I will conclude with a more speculative point on treatment of simultaneous activities. As our societies are transformed from a primarily agricultural and then a manufacturing society into an information-based society, the physical aspects of time use are becoming less important. The mental, social, and psychological aspects are becoming more important. The price of brainpower is rising relative to the price of horsepower. To the extent that the traditional time-use measures are locationally and physically oriented, they will miss this transition. This point suggests that moving toward a value-theoretic approach will help us understand the evolving nature of time and employ time-use surveys accurately in economic accounts.

\section{References}

Abraham, Katharine G., and Christopher Mackie, eds. 2005. Beyond the market: Designing nonmarket accounts for the United States. Washington, DC: National Academies Press. 
Adelman, M. A., and G. C. Watkins. 2003. Oil and natural gas reserve prices, 19822002. MIT Center for Energy and Environmental Policy Research. Working Paper, October.

Bolt, Katharine, Mampite Matete, and Michael Clemens. 2002. Manual for calculating adjusted net savings. Environment Department working paper. Washington, DC: World Bank, September.

Costanza, Robert, Ralph d'Arge, Rudolf de Groot, Stephen Faberk, Monica Grasso, Bruce Hannon, Karin Limburg, et al. 1997. The value of the world's ecosystem services and natural capital. Nature 387 (May): 253-60.

Fraumeni, Barbara F. 1999. The Jorgenson system of national accounting. In Econometrics and the cost of capital: Essays in honor of Dale W. Jorgenson, ed. Lawrence J. Lau, 111-42. Cambridge, MA: MIT Press.

Juster, F. Thomas. 1985. Preferences for work and leisure. In Time, goods and wellbeing, ed. F. Thomas Juster and Frank P. Stafford, 333-51. Ann Arbor, MI: Institute for Social Research.

Kahneman, Daniel, Alan B. Krueger, David A. Schkade, Norbert Schwarz, and Arthur A. Stone. 2004. A survey method for characterizing daily life experience: The day reconstruction method. Science 306 (December): 1776-80.

Nordhaus, William D., and Edward Kokkelenberg, eds. 2000. Nature's numbers: Expanding the national economic accounts to include the environment. Washington, DC: National Academy Press.

Nordhaus, William D., and James Tobin. 1972. Is growth obsolete? In Fiftieth anniversary colloquium $V$. New York: Columbia University Press.

Robinson, John, and Geoffrey Godbey. 1997. Time for life: The surprising ways Americans use their time. University Park, PA: Pennsylvania University Press.

United Nations. 1993. Integrated environmental and economic accounting: Interim version. Studies in Method, series F, no. 61. New York: United Nations. 